\title{
Spatial-Temporal Evolution Characteristics and Driving Factors of Agricultural Space in Jianghan Plain from the Perspective of "Three-Zone Space"
}

\author{
Wei Wei'1,2, Hao Xing1 \\ ${ }^{1}$ School of Urban Design of Wuhan University, Wuhan, China \\ ${ }^{2}$ China Institute of Development Strategy and Planning, Wuhan University, Wuhan, China \\ Email:1023822155@qq.com
}

How to cite this paper: Wei, W. and Xing, H. (2020) Spatial-Temporal Evolution Characteristics and Driving Factors of Agricultural Space in Jianghan Plain from the Perspective of "Three-Zone Space". Open Journal of Ecology, 10, 62-76. https://doi.org/10.4236/oje.2020.102005

Received: January 26, 2020

Accepted: February 24, 2020

Published: February 27, 2020

Copyright $\odot 2020$ by author(s) and Scientific Research Publishing Inc. This work is licensed under the Creative Commons Attribution International License (CC BY 4.0).

http://creativecommons.org/licenses/by/4.0/ (c) (i) Open Access

\begin{abstract}
Studying the agricultural spatial distribution characteristics of Jianghan Plain from 2000 to 2018 and its spatial-temporal transformation with ecological space and urban space is of great significance for optimizing the spatial structure of the country, enhancing the supply capacity of agricultural products, and ensuring food security. The research results show that during the period from 2000 to 2018, the agricultural spatial concentration in the area along the "Xiaogan-Jingzhou" link was relatively high, and the areas with large declines were mainly distributed in the flat areas between the Yangtze River and Han River; the space is continuously reduced by the occupation of ecological space and urban space, and ecological space and urban space have been improved respectively; agricultural space has been transformed into ecological space, and the largest urban space has been transformed. Ecological space has been transformed into agricultural space and urban space. Less urban space has been transformed into agricultural space and ecological space.
\end{abstract}

\section{Keywords}

Three-Zone Space, Jianghan Plain, Agricultural Space, Spatiotemporal Evolution, Driving Factors

\section{Introduction}

Agricultural space resources are the basic natural conditions for human beings to survive and develop. They are responsible for meeting people's food needs and are also the basic driving force for urban development [1] [2] [3]. From the perspective of human survival and sustainable development, a reasonable agri- 
cultural spatial pattern is an important guarantee for national food security. It is of great significance for optimizing the national spatial pattern, enhancing the supply of agricultural products, and promoting the healthy development of cities [4] [5] [6].

The current literature on agricultural space is mainly focused on three aspects: first, focusing on rural residents' villages, focusing on describing and analyzing the evolution of agricultural village space, and the evolution of the spatial pattern of rural settlements [7] [8] [9] [10]; second, focusing on the development of agricultural modernization, and studying the spatial distribution, types, measures and constraints of agricultural modernization development [11] [12] [13] [14] [15]; third, exploring the relationship between urbanization and cultivated land protection, and studying the root causes of the contradiction between urbanization and cultivated land protection, in order to achieve the protection of cultivated land and comprehensive coordination of urbanization and all land use [16] [17] [18] [19].

This article analyzes the agricultural spatial pattern distribution and spatial-temporal evolution characteristics of the Jianghan Plain in different periods, and quantifies the mutual transformation between agricultural space, ecological space, and urban space in combination with the "three-zone space" background of the current land space planning, and analyzes and studies the driving force behind it.

\section{Research Areas and Research Methods}

\subsection{Study Area}

The Jianghan Plain is located in the middle reaches of the Yangtze River and the central and southern parts of Hubei Province. It has an excellent climate, rich products, and developed agriculture. It is an important food producing area in China. A total of 21 counties (districts) including Jingzhou 2 districts, 3 cities and 3 counties, Yichang 2 cities, Jingmen 2 cities and 1 county, Xiaogan 2 cities and 1 county, Xianning 1 city and 1 county, and 3 cities directly managed by the province As the research object (see Figure 1), the total land area is $41,213.03$ $\mathrm{km}^{2}$, and the total population at the end of 2018 reached $15,128,800$.

\subsection{Data Sources}

The land use and "three-zone space" quantitative information involved in this article comes from Data Center for Resources and Environmental Sciences, Chinese Academy of Sciences (RESDC) (http://www.resdc.cn) [20], and is obtained through factor extraction and overlay analysis. The demographic and economic data involved are from the Statistical Yearbook of Hubei Province (2000-2018), statistical bulletins of counties (districts) and cities and government work reports.

\subsection{Research Method}

The ArcGIS technology was used to extract remote sensing data for land cover in 


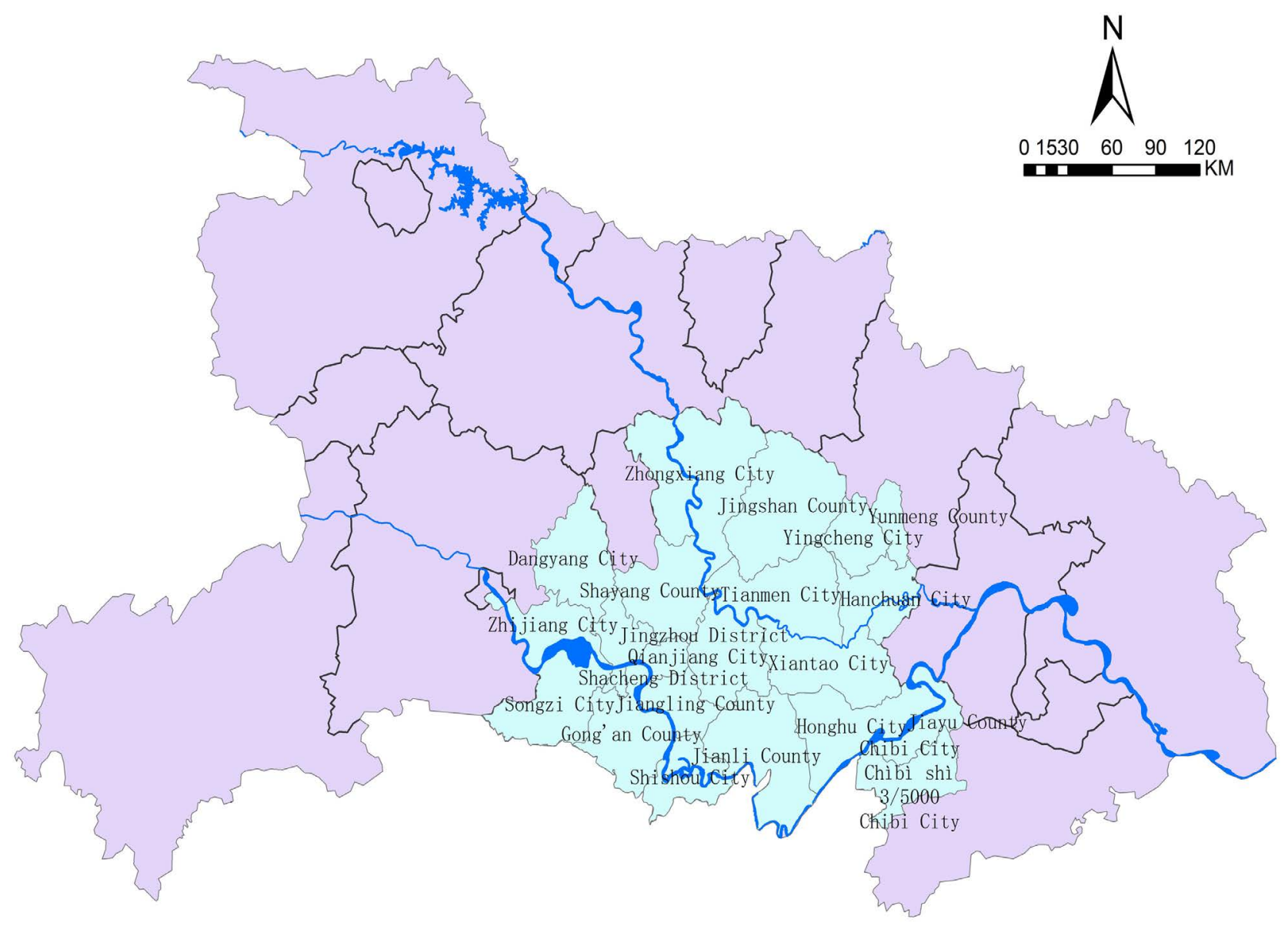

Figure 1. Location map of Jianghan Plain.

the Jianghan Plain in 2000, 2005, 2010, 2015, and 2018. According to the land use attributes, it was divided into six categories: cultivated land, forest land, grassland, waters, construction land and unused land. According to the "three-zone space" in the land space plan, the six types of space are integrated into three categories: agricultural space, ecological space, and urban space. Among them: agricultural space includes cultivated land, ecological space includes forest land, grassland, and water. Urban space is dominated by construction land. Unused land is included in urban space.

\section{Change Process Analysis}

\subsection{Total Change in Different Years}

It can be seen from Figure 2 that the agricultural space area of the Jianghan Plain continued to decline from 2000 to 2018, from 26,421.20 km² in 2000 to $25,495.72 \mathrm{~km}^{2}$ in 2018 , a decrease of $925.48 \mathrm{~km}^{2}$. During this period, the most significant changes were in $00-05$ and 10 - 15 years, which decreased by 391.58 $\mathrm{km}^{2}$ and $342.73 \mathrm{~km}^{2}$, respectively; in $05-10$, the downward trend was relatively gentle, which decreased by $148.54 \mathrm{~km}^{2}$; in $15-18$, the changes were the smallest and only decreased $42.63 \mathrm{~km}^{2}$. 


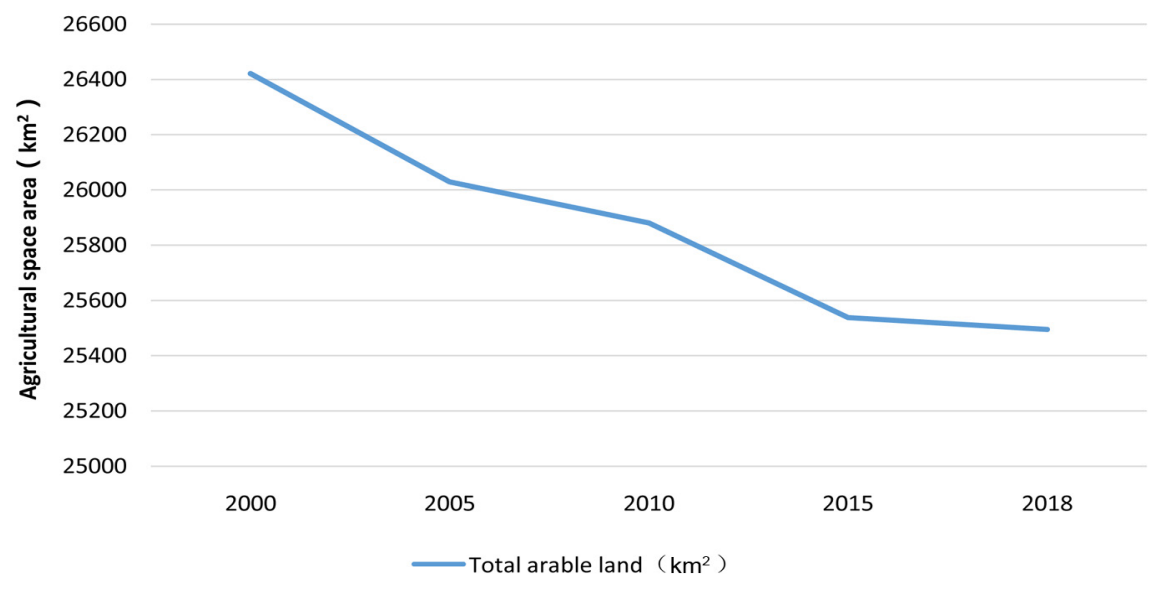

Figure 2. Changes in total agricultural space in different years.

\subsection{Spatial Distribution Map and Area Statistics of Agriculture in Different Regions and Years}

It can be seen from Figure 3 that the agricultural space in the Jianghan Plain is mainly concentrated and continuously distributed in Jingzhou District, Jiangling County, Jianli County, Shayang County, and Qianjiang City between the Yangtze River and Hanjiang River, and Gong'an County and Shishou south of the Yangtze River, as well as Tianmen, Hanchuan, Yingcheng and Yunmeng counties north of the Han River. Counties and cities with relatively sparse agricultural spatial distribution, such as Jingshan County and Honghu City, have a large area of non-agricultural space.

As can be seen from Table 1, the proportion of agricultural space in the Jianghan Plain has been decreasing year by year, and the proportion of agricultural space in each county (district) has also shown a gradual decline. Yunmeng, Jiangling, and Shayang counted as three agricultural counties with over $80 \%$ of agriculture in 2000. By 2018, only Yunmeng County has more than $80 \%$, and Jiangling and Shayang counties have fallen to $79.49 \%$ and $79.26 \%$, respectively. In 2000, 10 counties (districts) and cities accounted for more than $60 \%$ of agriculture, including Yingcheng City, Tianmen City, Gongan County, Qianjiang City, Jianli County, Jingzhou District, Hanchuan City, Shishou City, and Xiantao City. And Shacheng District, the Shacheng District will fall to $55.52 \%$ by 2018 , and other counties (districts) and cities will also show varying degrees of decline.

It can be seen from Figure 4 that from 2000 to 2018, the largest change in agricultural space was in Honghu City, which reached $177.76 \mathrm{~km}^{2}$; followed by Xiantao City, which fell by $143.95 \mathrm{~km}^{2}$; Jianli County, Qianjiang City, and Tianmen City with a change of more than $50 \mathrm{~km}^{2}$ They are $90.13 \mathrm{~km}^{2}, 55.11 \mathrm{~km}^{2}$, and $50.04 \mathrm{~km}^{2}$ respectively; the smallest change is in Yingcheng, which has only decreased by $10.9 \mathrm{~km}^{2}$.

\subsection{Location Quotient of Agricultural Space in Each County and City}

Using the concept of location quotient to analyze the degree of agricultural spatial 


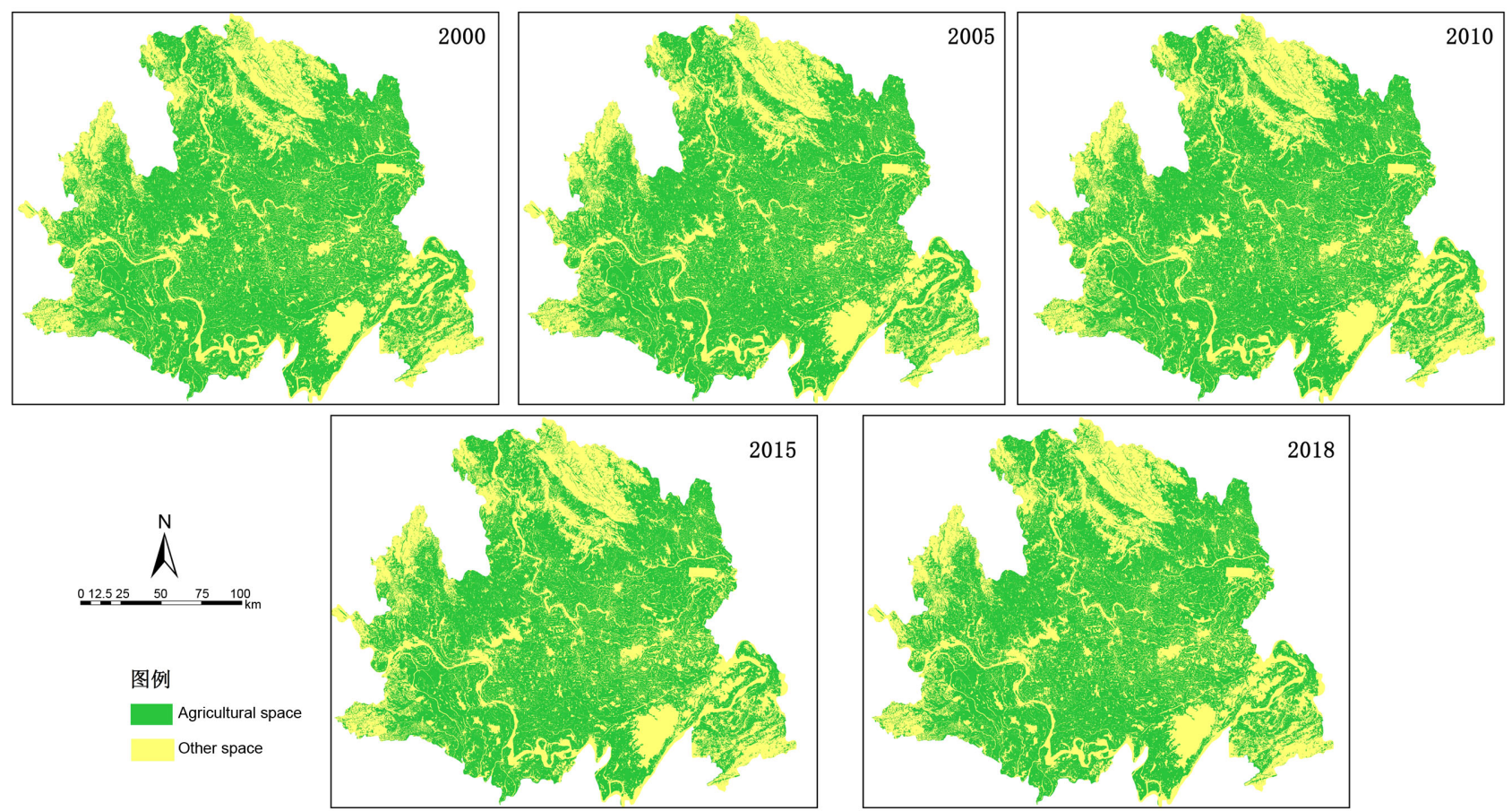

Figure 3. Agricultural spatial distribution of Jianghan Plain from 2000 to 2018.

200

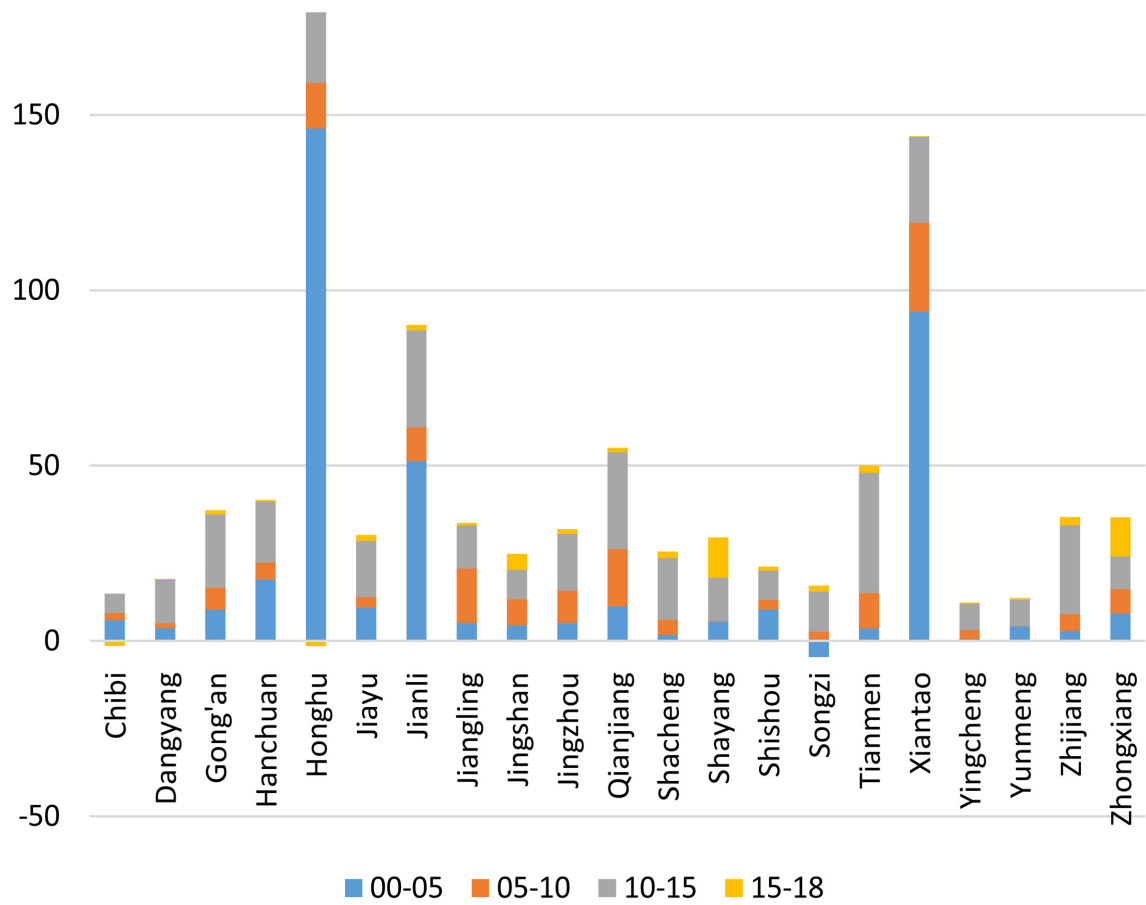

Figure 4. Spatial changes in agriculture by region, 2000-2018.

agglomeration and professionalization [21] [22], the calculation formula is:

$$
Q=\frac{a}{A} / \frac{b}{B}
$$


Table 1. Spatial data of agriculture in Jianghan Plain, 2000-2018.

\begin{tabular}{|c|c|c|c|c|c|c|c|c|c|c|c|}
\hline & & 20 & 00 & $20 c$ & 05 & 20 & 10 & 201 & 15 & 20 & 18 \\
\hline Name & $\begin{array}{l}\text { The } \\
\text { total } \\
\text { area }\end{array}$ & $\begin{array}{l}\text { Agricul-tural } \\
\text { space area } \\
\mathrm{km}^{2}\end{array}$ & Propor-tion & $\begin{array}{l}\text { Agricul-tural } \\
\text { space area } \\
\mathrm{km}^{2}\end{array}$ & Propor-tion & $\begin{array}{l}\text { Agricul-tura } \\
\text { space area } \\
\mathrm{km}^{2}\end{array}$ & Propor-tion & $\begin{array}{l}\text { Agricul-tural } \\
\text { space area } \\
\mathrm{km}^{2}\end{array}$ & Propor-tion & $\begin{array}{l}\text { Agricul-tura } \\
\text { space area } \\
\mathrm{km}^{2}\end{array}$ & Propor-tion \\
\hline Chibi & 1718.43 & 671.13 & $39.06 \%$ & 665.21 & $38.71 \%$ & 663.09 & $38.59 \%$ & 657.70 & $38.27 \%$ & 659.15 & $38.36 \%$ \\
\hline Dangyang & 2128.79 & 1025.30 & $48.16 \%$ & 1021.68 & $47.99 \%$ & 1020.23 & $47.93 \%$ & 1007.78 & $47.34 \%$ & 1007.61 & $47.33 \%$ \\
\hline Gong'an & 2268.14 & 1752.72 & $77.28 \%$ & 1743.82 & $76.88 \%$ & 1737.58 & $76.61 \%$ & 1716.61 & $75.68 \%$ & 1715.51 & $75.64 \%$ \\
\hline Hanchuan & 1663.66 & 1205.36 & $72.45 \%$ & 1187.84 & $71.40 \%$ & 1183.06 & $71.11 \%$ & 1165.56 & $70.06 \%$ & 1165.14 & $70.03 \%$ \\
\hline Honghu & 2511.76 & 1258.10 & $50.09 \%$ & 1111.95 & $44.27 \%$ & 1098.96 & $43.75 \%$ & 1078.85 & $42.95 \%$ & 1080.34 & $43.01 \%$ \\
\hline Jiayu & 1035.66 & 585.24 & $56.51 \%$ & 575.80 & $55.60 \%$ & 572.72 & $55.30 \%$ & 556.75 & $53.76 \%$ & 555.07 & $53.60 \%$ \\
\hline Jianli & 3133.29 & 2370.89 & $75.67 \%$ & 2319.62 & $74.03 \%$ & 2310.03 & $73.73 \%$ & 2282.35 & $72.84 \%$ & 2280.76 & $72.79 \%$ \\
\hline Jiangling & 1064.75 & 879.98 & $82.65 \%$ & 874.80 & $82.16 \%$ & 859.34 & $80.71 \%$ & 847.09 & $79.56 \%$ & 846.37 & $79.49 \%$ \\
\hline Jingshan & 3521.21 & 1600.73 & $45.46 \%$ & 1596.25 & $45.33 \%$ & 1588.87 & $45.12 \%$ & 1580.42 & $44.88 \%$ & 1575.96 & $44.76 \%$ \\
\hline Jingzhou & 1035.50 & 783.48 & $75.66 \%$ & 778.37 & $75.17 \%$ & 769.14 & $74.28 \%$ & 752.94 & $72.71 \%$ & 751.57 & $72.58 \%$ \\
\hline Qianjiang & 2024.36 & 1535.60 & $75.86 \%$ & 1525.75 & $75.37 \%$ & 1509.35 & $74.56 \%$ & 1481.74 & $73.20 \%$ & 1480.48 & $73.13 \%$ \\
\hline Shacheng & 490.08 & 297.56 & $60.72 \%$ & 295.90 & $60.38 \%$ & 291.51 & $59.48 \%$ & 273.96 & $55.90 \%$ & 272.07 & $55.52 \%$ \\
\hline Shayang & 2166.99 & 1746.98 & $80.62 \%$ & 1741.51 & $80.37 \%$ & 1741.37 & $80.36 \%$ & 1728.97 & $79.79 \%$ & 1717.49 & $79.26 \%$ \\
\hline Shishou & 1416.15 & 959.99 & $67.79 \%$ & 951.07 & $67.16 \%$ & 948.32 & $66.96 \%$ & 939.99 & $66.38 \%$ & 938.83 & $66.29 \%$ \\
\hline Songzi & 2173.35 & 1263.28 & $58.13 \%$ & 1267.91 & $58.34 \%$ & 1265.30 & $58.22 \%$ & 1253.89 & $57.69 \%$ & 1252.15 & $57.61 \%$ \\
\hline Tianmen & 2639.98 & 2096.41 & $79.41 \%$ & 2092.84 & $79.27 \%$ & 2082.76 & $78.89 \%$ & 2048.47 & $77.59 \%$ & 2046.37 & $77.51 \%$ \\
\hline Xiantao & 2526.23 & 1701.12 & $67.34 \%$ & 1607.26 & $63.62 \%$ & 1581.90 & $62.62 \%$ & 1557.38 & $61.65 \%$ & 1557.17 & $61.64 \%$ \\
\hline Yingcheng & 1084.02 & 858.61 & $79.21 \%$ & 858.10 & $79.16 \%$ & 855.51 & $78.92 \%$ & 847.97 & $78.22 \%$ & 847.70 & $78.20 \%$ \\
\hline Yunmeng & 611.21 & 519.62 & $85.01 \%$ & 515.42 & $84.33 \%$ & 515.39 & $84.32 \%$ & 507.91 & $83.10 \%$ & 507.42 & $83.02 \%$ \\
\hline Zhijiang & 1564.94 & 921.56 & $58.89 \%$ & 918.80 & $58.71 \%$ & 913.91 & $58.40 \%$ & 888.59 & $56.78 \%$ & 886.26 & $56.63 \%$ \\
\hline Zhongxiang & 4434.53 & 2387.54 & $53.84 \%$ & 2379.74 & $53.66 \%$ & 2372.75 & $53.51 \%$ & 2363.46 & $53.30 \%$ & 2352.31 & $53.05 \%$ \\
\hline total & $41,213.03$ & $26,421.20$ & $64.11 \%$ & $26,029.62$ & $63.16 \%$ & $25,881.03$ & $62.80 \%$ & $25,538.35$ & $61.97 \%$ & $25,495.72$ & $61.86 \%$ \\
\hline
\end{tabular}

In the formula, $Q$ represents the location quotient, a represents the agricultural space area of a county (district) city, $A$ represents the total land area of the county (district) city, $b$ represents the agricultural space area of the whole region, and $B$ represents the total land area of the whole region.

It can be seen from Figure 5 and Figure 6 that from 2000 to 2018, Yunmeng County, Jiangling County, and Shayang County have always been in the top three agricultural space quotients, indicating that Yunmeng, Jiangling, and Shayang have a high degree of agricultural spatial concentration. Compared with other counties (districts) and cities in the Jianghan Plain, it has a comparative advantage; in 2000, there were 9 regions with a location quotient greater than 1 , and they were Tianmen City, Yingcheng City, Gong'an County, Qianjiang City, Jianli County, Jingzhou District, Hanchuan City, Shishou City, and Xiantao City 


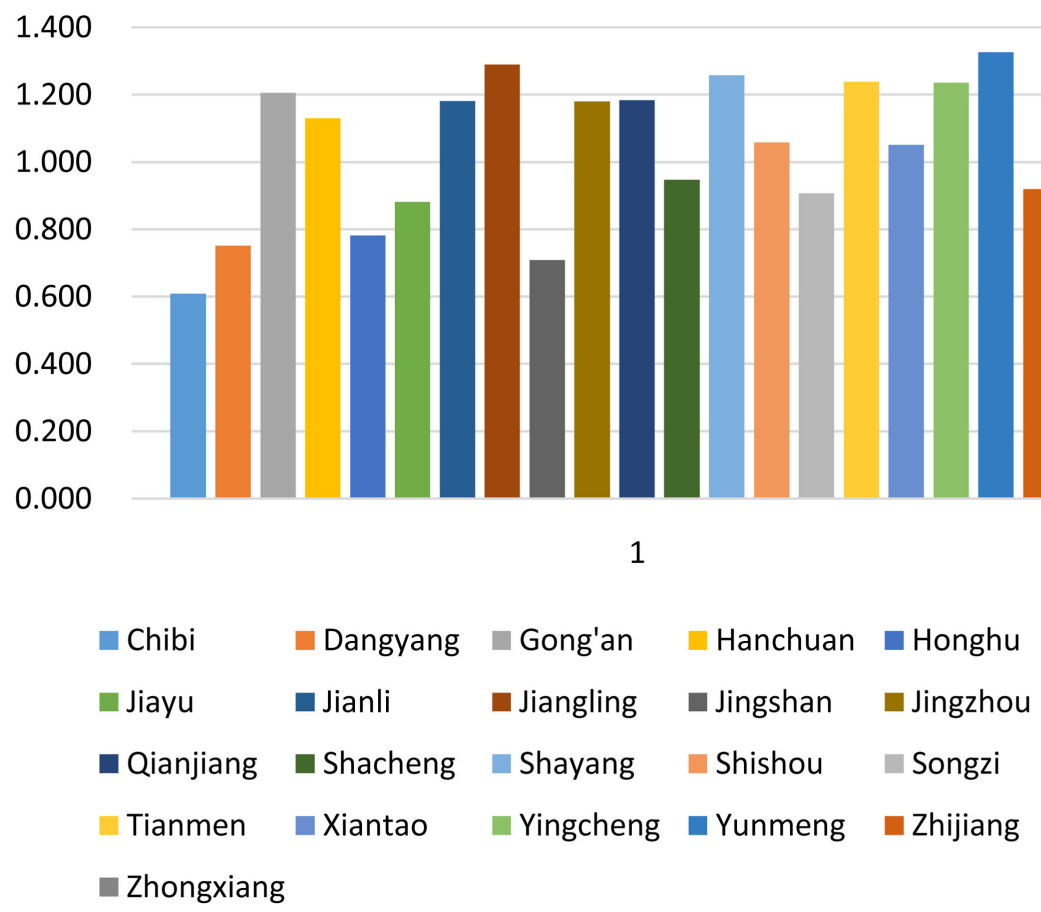

Figure 5. Location quotient of agricultural space by region in 2000 .

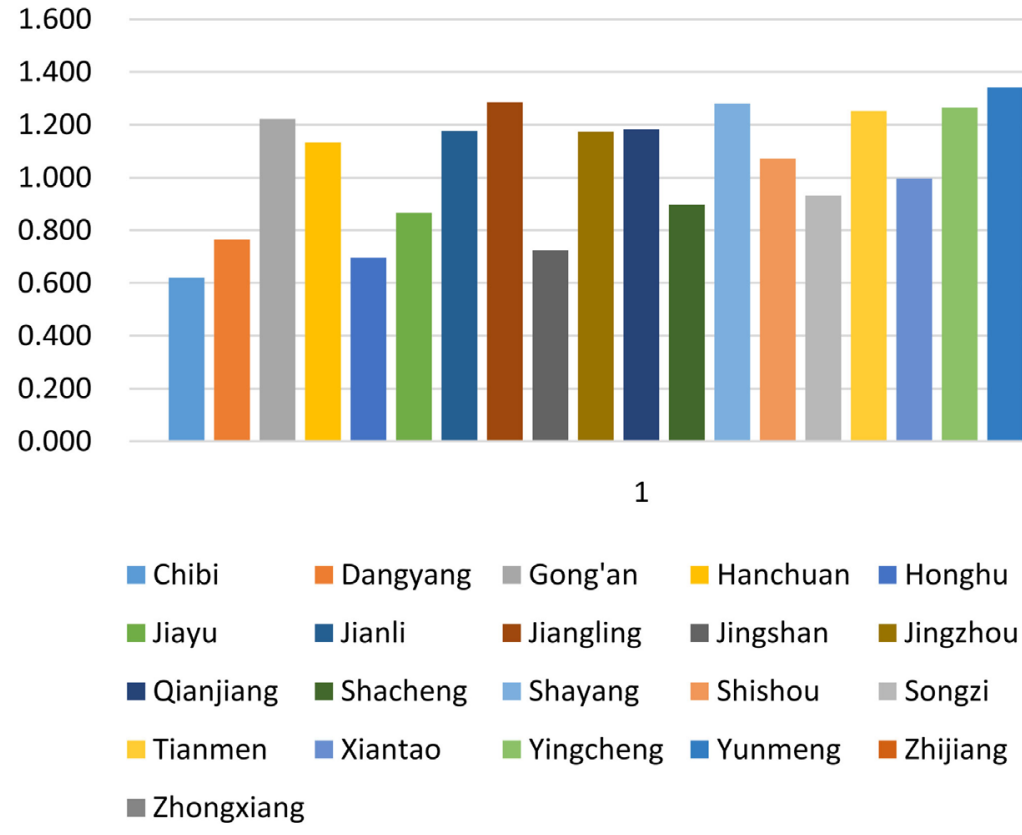

Figure 6. Location quotient of agricultural space by region in 2018 .

will fall to eight by 2018, of which Xiantao City has dropped below 1, indicating that the agricultural space of Xiantao City has changed significantly; Chibi City, Honghu City, Jingshan, and Dangyang have changed in the past 18 years.

Based on the location quotient, and the analysis of relevant data, using GIS to draw the spatial distribution map of the agricultural space location quotient of the Jianghan Plain from 2000 to 2018 (Figure 7), we can see that the administrative 

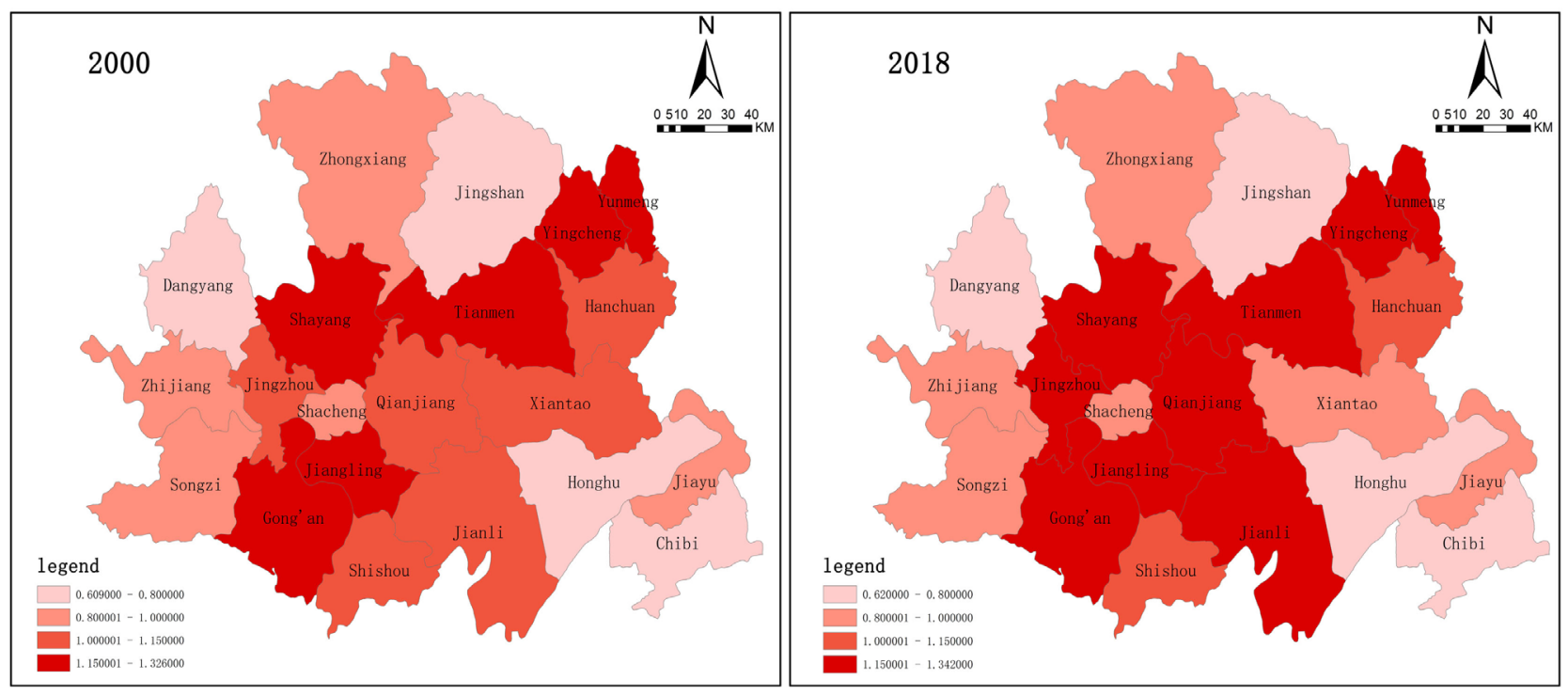

Figure 7. Spatial distribution map of agricultural spatial location quotients by region in 2000 and 2018.

units with a higher degree of agricultural spatial concentration are distributed in a centralized and continuous pattern. The spatial pattern is belt-shaped, mainly located between the Yangtze River and the Han River and in areas extending northeast and spreading southward, that is, the direction of the "Xiaogan-Jingzhou" connection has the largest agricultural spatial density, and decreases with the spread to both sides small.

\section{4. "Three-Zone Space” Distribution Characteristics}

The land space is divided into three categories: agricultural space, ecological space, and urban space. GIS is used to draw the spatial distribution maps of the three districts in different years in the Jianghan Plain, and the area of the three types of space is quantified to obtain Figure 8, Table 2.

The analysis shows that in the past 18 years, agricultural space has been continuously occupied by ecological space and urban space and has declined; although ecological space has also been continuously occupied by urban space, it has increased due to the simultaneous occupation of agricultural space; urban space has shown an upward trend year by year.

On the whole, the "three-zone space" in the Jianghan Plain has not risen or fallen violently. After nearly 20 years of rapid economic development, the proportion of various types of space has not changed significantly, and the territorial space structure remains relatively stable.

\section{5. "Three-Zone Space" Mutual Transformation Characteristics}

Based on the "three-zone space" distribution map of the Jianghan Plain, Arcgis was used to superimpose land properties, and the conversion relationship between the "three-zone space" in each county (district) and city from 2000 to 2018 was obtained and quantified (Figure 9). 


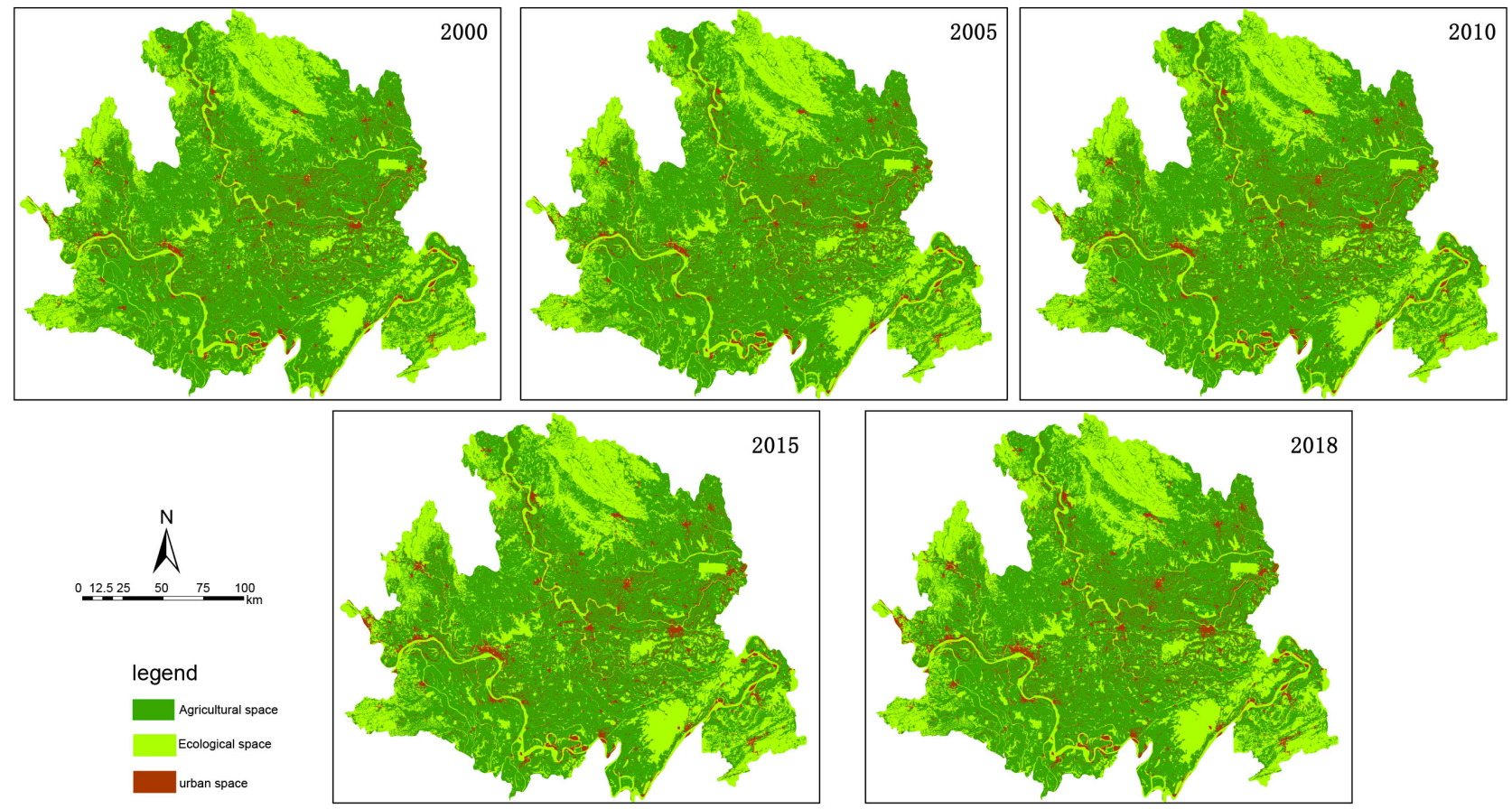

Figure 8. “Three-zone space” distribution map of Jianghan Plain from 2000 to 2018.

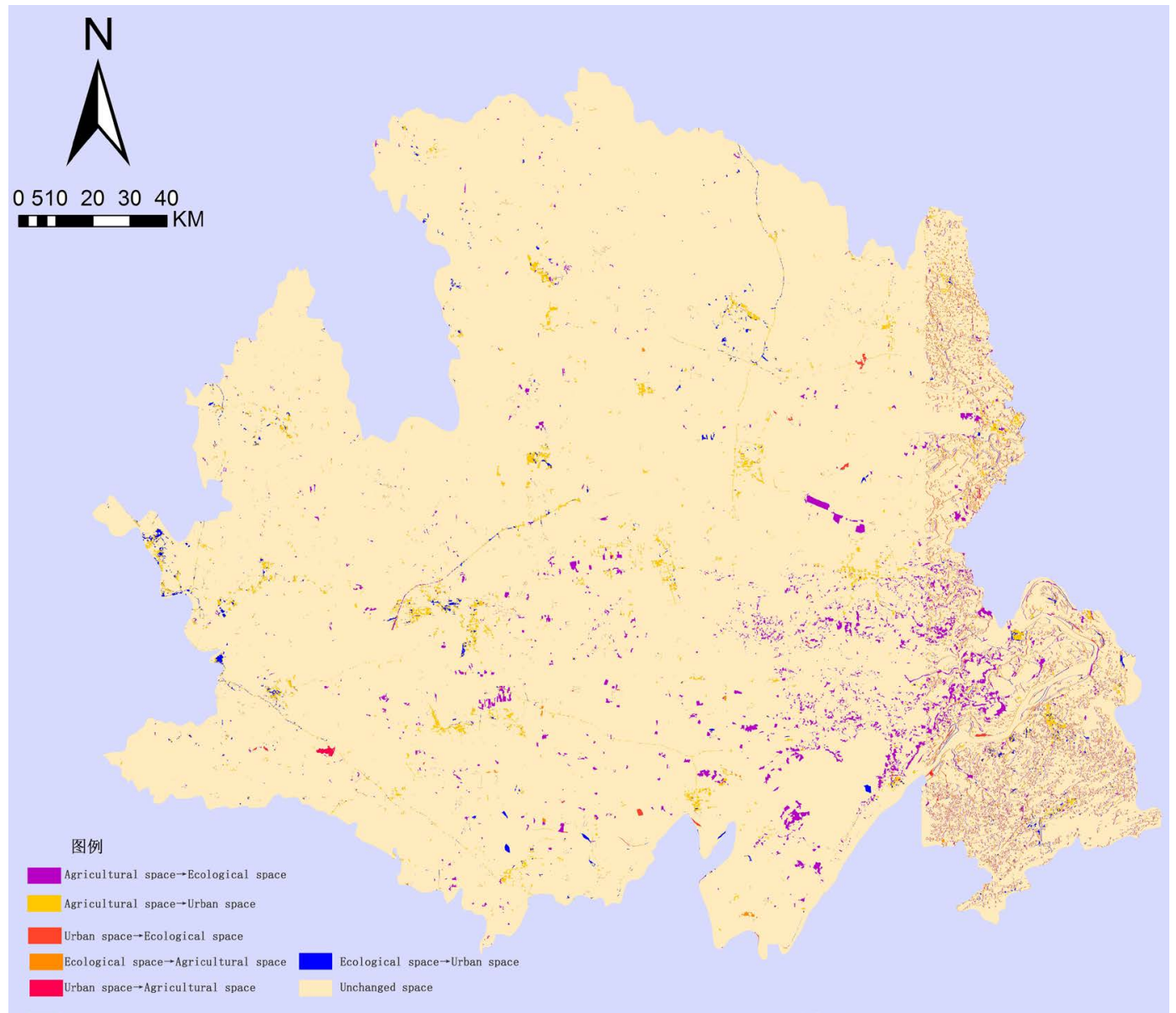

Figure 9. “Three-zone space” conversion map of Jianghan Plain from 2000 to 2018. 
Table 2. Data of "three-zone space" in Jianghan Plain from 2000 to 2018.

\begin{tabular}{|c|c|c|c|c|c|c|c|c|c|c|}
\hline & \multicolumn{2}{|c|}{2000} & \multicolumn{2}{|c|}{2005} & \multicolumn{2}{|c|}{2010} & \multicolumn{2}{|c|}{2015} & \multicolumn{2}{|c|}{2018} \\
\hline & $\begin{array}{l}\text { Land area } \\
\left(\mathrm{km}^{2}\right)\end{array}$ & Proportion & $\begin{array}{l}\text { Land area } \\
\left(\mathrm{km}^{2}\right)\end{array}$ & Proportion & $\begin{array}{l}\text { Land area } \\
\qquad\left(\mathrm{km}^{2}\right)\end{array}$ & Proportion & $\begin{array}{l}\text { Land area } \\
\left(\mathrm{km}^{2}\right)\end{array}$ & Proportion & $\begin{array}{l}\text { Land area } \\
\left(\mathrm{km}^{2}\right)\end{array}$ & Proportion \\
\hline $\begin{array}{l}\text { Agricultural } \\
\text { space }\end{array}$ & $26,421.20$ & $64.11 \%$ & $26,029.62$ & $63.16 \%$ & $25,881.07$ & $62.80 \%$ & $25,538.35$ & $61.97 \%$ & $25,495.72$ & $61.86 \%$ \\
\hline $\begin{array}{l}\text { Ecological } \\
\text { space }\end{array}$ & $11,908.10$ & $28.89 \%$ & $12,265.83$ & $29.76 \%$ & $12,318.72$ & $29.89 \%$ & $12,331.16$ & $29.92 \%$ & $12,322.55$ & $29.90 \%$ \\
\hline $\begin{array}{l}\text { Urban } \\
\text { space }\end{array}$ & 2883.73 & $7.00 \%$ & 2917.58 & $7.08 \%$ & 3013.24 & $7.31 \%$ & 3343.52 & $8.11 \%$ & 3394.77 & $8.24 \%$ \\
\hline Total & $41,213.03$ & $100.00 \%$ & $41,213.03$ & $100.00 \%$ & $41,213.03$ & $100.00 \%$ & $41,213.03$ & $100.00 \%$ & $41,213.03$ & $100.00 \%$ \\
\hline
\end{tabular}

The analysis shows that: 1) The transformation of agricultural space into the largest ecological space, especially in Honghu City, Xiantao City, Chibi City and Jianli County, the scale of transformation is the most prominent, and has become the largest administrative unit of spatial function transformation in 18 years. These areas are rich in Water resources; 2) The conversion of agricultural space into urban space appears to varying degrees in counties (districts) and cities, and has become the mainstream trend of spatial conversion in most administrative units; 3) The conversion of ecological space into agricultural space Chibi City is the most obvious, followed by Jiayu County and Honghu City; 4) The conversion of ecological space into urban space is also more significant, of which Zhijiang City, Jiayu County, Honghu City, and Jingshan County have a larger increase; 5) The scale of transformation into agricultural space is relatively small, mainly distributed in Hanchuan City, Yunmeng County, Honghu City and other places; 6) Urban space is transformed into the least ecological space, mainly concentrated in Chibi City, Jiayu County, Hanchuan City and other places.

\section{Driving Factor Analysis}

\subsection{Physical Geography}

The natural geographical environment is the foundation that affects the composition and use of land and space, and often combined with factors such as location conditions and human history to determine the distribution characteristics of the "three-zone space" in the Jianghan Plain: 1) Jingzhou has been the main production area of grain, cotton, and aquatic products. 2) Zhongxiang City, Jingshan County in the north of the Jianghan Plain, and the western and southeastern areas are mostly mountainous and hilly, its functions are more significant; 3) Hanchuan City, Xiantao City, and Jiayu County in the eastern part of the Jianghan Plain are located in the Wuhan City Circle, which is driven and affected by the regional growth poles; Zhijiang City and Dangyang City are located in Yichang Provincial Deputy Center has unique advantages in infrastructure construction and industrial structure optimization. Urban spatial expansion 
trend is more pronounced.

\subsection{Policy Promotion}

From the 18th National Congress of the People's Republic of China to respecting nature, complying with nature, and protecting nature, the idea of ecological civilization, to the 19th National Congress of the Communist Party of China, insisting on the harmonious coexistence of man and nature, in this context, Hubei Province promulgated more Policy articles such as "Plan for Hubei Province's Main Function Areas" (2012), "Outline of Hubei Ecological Province Construction Plan (2014-2030)" (2014), "Hubei Hanjiang Ecological Economic Belt Open Development Master Plan (2014-2025)” (2015), “Special Plan for Industrial Green Development of the Yangtze River Economic Belt in Hubei” (2017), etc. These policies provide institutional guarantees and management tools for the expansion of ecological space and urban space in the Jianghan Plain from aspects of ecological environmental protection and transformation of industrial development methods.

\subsection{Population Migration and Accelerated Urbanization}

According to the statistics of the population of Jianghan Plain from 2000 to 2018, we obtained the population change trend chart (Figure 10). The analysis shows that the total population of Jianghan Plain has been decreasing year by year, a decrease of $10.47 \%$, from $29.93 \%$ of the total population of Hubei Province in 2000 to $25.57 \%$ in 2018, but the number of urban population increased by $3,292,100$, an increase of $59 \%$, exceeding the $56 \%$ increase in urban population in Hubei Province during the same period, and the urbanization rate also increased from $31.62 \%$ in 2000 to $56.00 \%$ in 2018 . Therefore, during this period, a large number of people flooded into towns, the urban construction land continued to expand, and the increase in urban space was a significant phenomenon. At the same time, the rural population in the Jianghan Plain fell by $39.27 \%$,

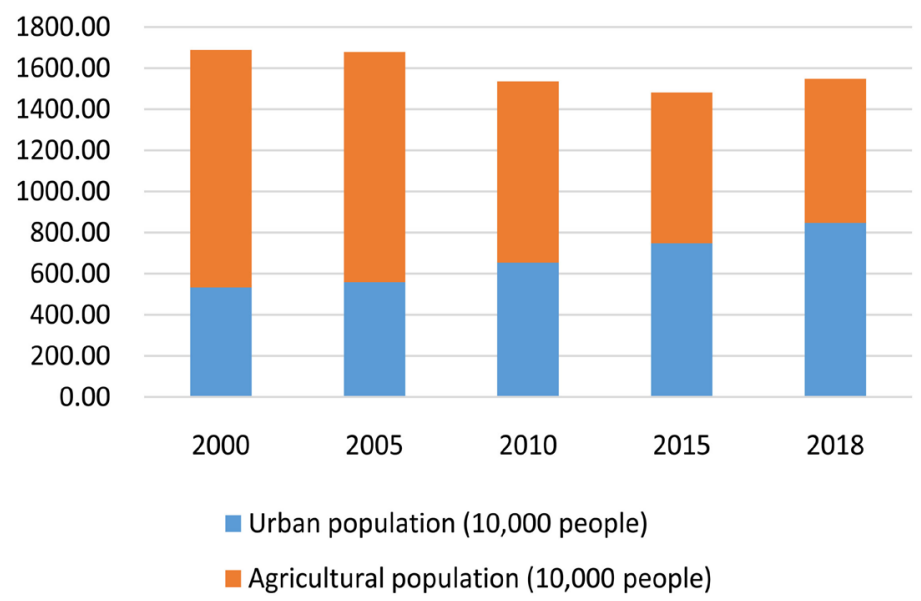

Figure 10. Trend of population change in Jianghan Plain from 2000 to 2018. 
far exceeding the $30.11 \%$ decline in rural population in Hubei Province during the same period. The outward migration of the population has led to the emergence of wasteland and wasteland in many places, coupled with the increase in agricultural output and production efficiency, leading to the constant shrinking of agricultural space.

\subsection{Economic Development and Industrial Structure Transformation}

Statistics on the industrial development of the Jianghan Plain from 2000 to 2018 can be found in Figure 11. The analysis shows that: 1) In terms of industrial structure changes, the growth rates of the primary, secondary, and tertiary industries have reached $368.90 \%, 894.14 \%$, and $738.14 \%$, respectively. The development is more than twice that of the primary industry, and the proportion of tertiary industry has also changed from 26.5:41.1:32.4 in 2000 to 15.4:50.8:33.8 in 2018. This is in line with the increase in urban space and ecological space in the Jianghan Plain. Consistent with the trend; 2) Compared with Hubei Province's tertiary industry ratios of 18.7:40.5:40.8 and 9.0:43.4:47.6 in 2000 and 2018, the proportion of the primary industry in the Jianghan Plain is always much higher than the provincial average. This is determined by the positioning of the main grain producing areas of the Jianghan Plain and good geographical conditions, natural environment, and historical development; the proportion of the secondary industry and the province's average ratio have gradually increased, indicating that the Jianghan Plain actively optimizes and adjusts its industries Structure and achieved certain results.

\section{Conclusions}

Taking the agricultural space of Jianghan Plain as an object, the spatial distribution and evolution rules of 2000, 2005, 2010, 2015, and 2018 were analyzed, and

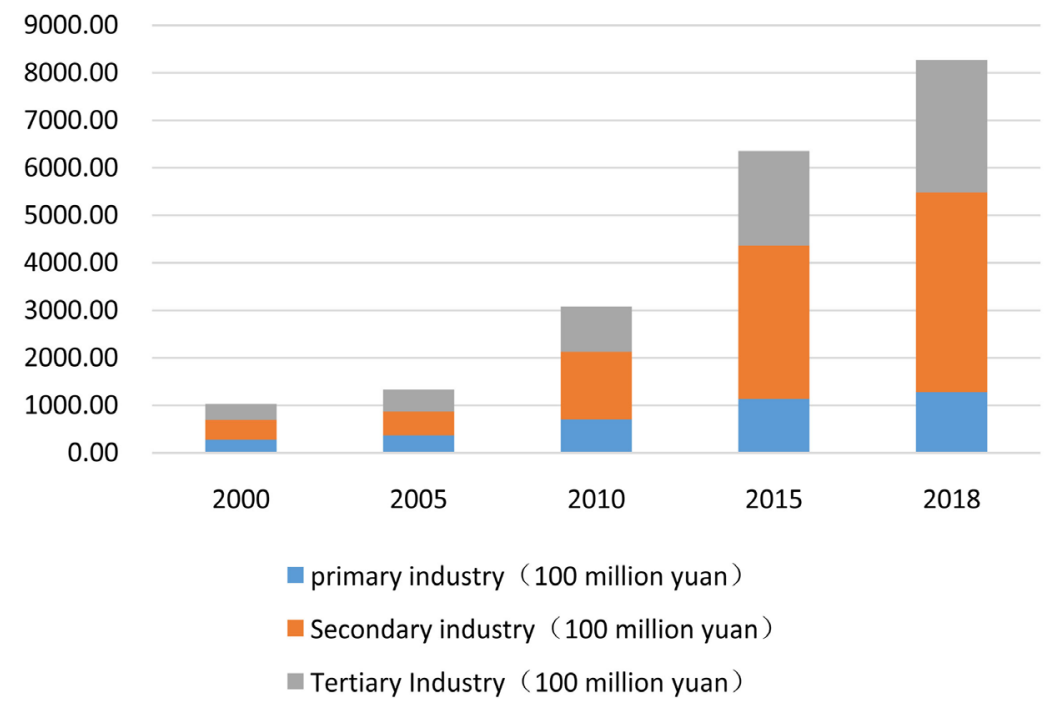

Figure 11. Trend of industrial changes in Jianghan Plain from 2000 to 2018. 
the spatial and temporal evolution of agricultural space, ecological space, and urban space were analyzed from the perspective of "three-zone space". The relationship between the three regions is analyzed from the aspects of physical geography, policy promotion, population migration and acceleration of urbanization, economic development and industrial structure transformation. The main conclusions are as follows:

1) The regions with a high degree of agricultural spatial concentration are distributed in the direction of the "Xiaogan-Jingzhou" connection; the areas with relatively small changes in agricultural space, that is, the regions with a large decline, are mainly distributed in the relatively flat terrain between the Yangtze and Han;

2) Agricultural space continues to be occupied by ecological space and urban space and declines. Although ecological space is also continuously occupied by urban space, it is increasing due to the simultaneous occupation of agricultural space, and urban space continues to expand and shows a rising trend year by year;

3) The transformation of agricultural space into ecological space has the largest scale; the transformation of agricultural space into urban space has appeared to varying degrees in each administrative unit and has become the mainstream trend of spatial transformation in most administrative units; the conversion of ecological space into agricultural space and towns space is also significant; less urban space is transformed into agricultural space and ecological space;

4) Natural geography conditions, location conditions, human history, and other factors work together to determine the distribution characteristics of the "three-zone space" in the Jianghan Plain; the national and provincial governments have issued a series of policies to provide for the expansion of the ecological space and urban space in the Jianghan Plain. But institutional safeguards and management methods still need to be further explored in terms of bottom-line control; the sharp increase in urban and rural population has become a powerful driving force for urban space expansion and agricultural space compression; changes in the industrial structure. The correlation mechanism between the change of industrial structure and the spatial structural adjustment it brings is very obvious. The adjustment of the proportion of the three industries provides a strong guide for the expansion of urban space and ecological space.

\section{Conflicts of Interest}

The authors declare no conflicts of interest regarding the publication of this paper.

\section{References}

[1] Zhao, X.L., Zhang, Z.X., Wang, X., Zuo, L.J., Liu, B., Yi, L., Xu, J.Y. and Wen, Q.K. (2014) Analysis on the Spatiotemporal Characteristics of Cultivated Land Changes and Their Main Reasons in China during the Past 30 Years. Transactions of the Chinese Society of Agricultural Engineering, 30, 1-11. 
[2] Guo, H.H. and Song, M. (2009) Analysis of Dynamic Change Trend and Driving Forces of Cultivated Land in Shandong Province. China Agricultural Resources and Regional Planning, 30, 51-57.

[3] Yi, B.Z. and Zhang, L.W. (2011) Research on the Development Trend of Agricultural Space Based on ROXY Index-Taking Inner Mongolia Autonomous Region as an Example. Dongjiang Academic Journal, 28, 85-90.

[4] Wang, Y.H. and Ma, M. (2018) The Spatial Distribution Pattern and Evolution of China's Agricultural Modernization Development Level. Jianghan Forum, No. 2, 30-35.

[5] Sun, Y. and He, Q. (2019) Study on the Differences in the Choice of Agricultural Management Models from the Perspective of Space-Empirical Analysis Based on Provincial Panel Data. Journal of Xi'an University of Finance and Economics, 32, 90-96.

[6] Wei, S.H., Liu, Y.R., Gao, Y.L. and Zong, G. (2019) Evaluation of China’s Agricultural Modernization and Its Spatial Pattern Evolution. Journal of Zhejiang Agricultural Sciences, 31, 1012-1020.

[7] Fang, Y.G. and Liu, J.S. (2009) Evolution Process and Mechanism of Cultural Landscape of Agglomerated Agricultural Villages: A Case Study of Qukou Village, Qufu, Shandong. Geographical Research, No. 4, 118-128.

[8] Mao, D.M. (2015) A Typical Case Study on the Spatial Evolution Trend of Agricultural Villages in Central China. 2015 China Urban Planning Annual Meeting.

[9] Chen, J. and Zhang, L. (2014) The Evolution Mechanism and Case Analysis of Rural Settlements in the Urban-Rural Fringe-A Study from the Perspective of New Institutionalism. Urban Development Research, 21, 18-23.

[10] Yang, Y., Deng, X.Z., Wu, F., et al. (2019) Analysis of the Evolution of Rural Settlements in the North China Plain and Its Socioeconomic Factors. Human Geography, 34, 122-130.

[11] Wang, Y.H. and Ma, M. (2014) The Spatial Distribution Pattern and Evolution of China's Agricultural Modernization Development Level. Jianghan Forum, No. 476, 32-37.

[12] Long, D.P., Miao, Y.Y., Yu, Z.S., et al. (2014) Spatial Differentiation and Types of Agricultural Modernization in China. Acta Geographica Sinica, 69, 213-226. https://doi.org/10.5194/gh-69-213-2014

[13] Li, L.C. (2013) Analysis of China's Agricultural Modernization Level Measurement and Fluctuation Trend Analysis Based on Grey Advantage Analysis. Economic Geography, No. 8, 118-122.

[14] Liu, X.L. (2016) Measurement and Empirical Research on the Comprehensive Development Level of Agricultural Modernization. Chengdu University of Technology, Chengdu.

[15] Chen, Q.Q., Sun, X.H., Lu, J.P. and Li, X. (2018) Study on the Measurement and Restrictive Factors of Agricultural Modernization in Gansu Province. Research of Agricultural Modernization, 39, 13-21.

[16] Wei, H.Y. and Zhang, J. (2006) Study on the Relationship between Urbanization Level and Cultivated Land Area Change: A Case Study of Shaanxi Province. Journal of Northwest University: Natural Science Edition, 36, 157-160.

[17] Wei, Y. (2012) Study on the Spatiotemporal Pattern Evolution of Urbanization and Cultivated Land Protection in Mang City, Yunnan. Yunnan University of Finance and Economics, Kunming. 
[18] Wang, X. (2009) On Urbanization Construction and Cultivated Land Protection. Academic Exchange Conference on Applied Technology of Modern Construction Engineering.

[19] Li, X.D. (2011) Analysis on the Measurement and Coordination of Urbanization Development and Cultivated Land Resources in Guizhou Province. Journal of De mography, No. 1, 79-86.

[20] Xu, X.L., Liu, J.Y., Zhang, S.W., Li, R.D., Yan, C.Z. and Wu, S.X. (2018) China's Multi-Period Land Use Land Cover Remote Sensing Monitoring Dataset (CNLUCC). Data Registration and Publishing System of the Resource and Environmental Science Data Center of the Chinese Academy of Sciences.

[21] Ni, W.Q. and Meng, C. (2012) Analysis of Land Use Structure Based on Spatial Lorentz Curve and Gini Coefficient: A Case Study of Heilongjiang Province. Land and Resources Science and Technology Management, 29, 51-57.

[22] Li, D., Xu, S., Han, D.B. and Wang, X. (2014) Land Use Status Analysis Based on RS and GIS. Journal of Heilongiiang Institute of Technology, 28, 27-30+37. 